\title{
Cultura da diversidade: uma orientação teórica para a prática cultural de cooperação social ${ }^{1}$
}

Thomas Bauer

Resumo: O objetivo deste artigo é refletir criticamente sobre a questão da diversidade cultural, apoiando-se em teorias culturais e em aspectos da comunicação. Por cultura, compreende-se um processo circular que envolve variedade, pluralidade e atravessamento de distintas perspectivas, não se restringindo a teorias específicas e segmentadas. Nesse sentido e afiliada à cultura, a diversidade se expressa como organismo plural e híbrido, projetando-se nos processos comunicacionais nos quais o outro (a diversidade) é parte intrínseca constituinte. Sendo, portanto, a comunicação uma outra face da cultura (e vice-versa), afirmamos que cabe à mídia proporcionar reflexões críticas sobre o funcionamento da sociedade, ampliando o debate sobre diversidade e configurando seu caráter híbrido e plural.

Palavras-chave: cultura; diversidade; comunicação.

Abstract: A theoretical guidance for the cultural practice of social cooperation - The purpose of this article is to reflect critically on the issue of cultural diversity, supported by cultural theories and aspects of communication. Culture is perceived as a circular process that involves variety, plurality and crossing different perspectives, not limited to specific and targeted theories. In this sense and affiliated with culture, diversity is expressed as plural and hybrid organism, projected in communicative processes in which the other (diversity) is a constituent intrinsic part. Being, therefore, communication another face of culture (and vice versa), we affirm that one of media's purpose is to provide critical reflections about society, widening the debate on diversity and configuring its hybrid and plural character.

Keywords: culture; diversity; communication.

Para explicar o que é ou o que seria a cultura da diversidade, é necessário escolher um quadro referencial, que seja significativo e relevante, para pensar a questão. Trata-se

1 Versão reformulada de texto originalmente publicado em: BAUER, T. A.; ORTNER, G. E. (ed.) Werte für Europa. Medienkultur und ethische Bildung in und für Europa, 2006. p. 242- 267. 
de um simples requisito, caso contrário, não seria possível uma argumentação politicamente sincera sobre como desenvolver ou como estabelecer a cultura da diversidade - sem falar na necessidade de responder honestamente à seguinte questão: qual a necessidade de cultivar a diversidade? Obviamente, o termo diversidade ocupa uma posição paradigmática na compreensão e explicação do problema da unidade social. A diversidade torna-se um termo cultural e político usado nos contextos de novos horizontes conceituais sobre as sociedades. Não há conceito de referência mais esclarecedor do que o conceito de comunicação, já que a comunicação é a instância que unifica a diferença e nos faz entender a diversidade como um desafio da cultura.

\section{Aproximação epistemológica: falando sobre cultura}

A insinuação de criar uma declaração significativa sobre cultura da diversidade só é possível se aceitarmos, igualmente, a obrigação de construirmos uma declaração significativa sobre a diversidade da cultura. Se optarmos por uma teoria da cultura, estaremos optando por uma cultura da teoria. Se escolhermos um modelo teórico aberto de aprendizagem, nós estaremos teorizando um modelo de aprendizado aberto sobre a cultura. Nesse sentido, cultura é um open software, que acontece na própria aprendizagem (reflexo) por meio do seu próprio uso. A cultura existe na necessidade de enfrentamentos provocados por interrupções reflexivas (SCHIMIDT, 2004, p. 59), que se tornam parte dela, pois a cultura está em um processo comunicativo circular, comunicação sobre comunicação.

A observação da cultura é possível no enquadramento cultural da observação. Como a observação é uma maneira de marcar um posicionamento na comunicação (compreensão) sobre o que está sendo falado, a chave da observação é a comunicação. O mais complexo na experiência de conectividade social (sociedade) torna-se o mais importante, o que compensará momentos e fatores de incerteza, que só podem ser geridos por instâncias de auto-observação, que incorporem a crescente complexidade. Assim, a sociedade acredita garantir certeza de controle. Ao mesmo tempo, o mundo da realidade social passa a ser mais aberto e mais causal. Além de todos os processos de sistematização (ex.: pela mídia), a sociedade tenta encontrar uma saída para todos os fortes protocolos da tradição e descobrir horizontes de orientação em si mesma e na sua própria execução. Ou seja, a sociedade, que cada vez mais está envolta em paradigmas, reflete menos sobre as condições de formações contínuas do que sobre os desafios da transformação. Cultura e comunicação são paradigmas semelhantes. Eles são teoricamente (GIDDENS, 1990; HALL, 1998) e politicamente, cada vez mais, interpretados como um modelo de base de uma sociedade aberta e autorresponsável. Nesse gesto (cultural) de atenção autorreflexiva, a sociedade aprende e, então, chega a uma melhor prática. Cultura e comunicação se explicam mutuamente no contexto da autorreflexão. Elas são cada uma um lado da moeda (que é a sociedade): um lado não é negociável sem 
o outro. Apesar disso, elas são competências de práticas sociais distintas. A fragilidade da cultura sempre é a fragilidade da comunicação. A vulnerabilidade da cultura é comunicativa, e a vulnerabilidade da comunicação é cultural.

Uma compreensão culturológica da comunicação (BAUER, 2003a) parece ser o enquadramento teórico correto, no qual faz sentido refletir sobre problemas e soluções da diversidade. E mais: uma análise baseada na teoria da comunicação da diversidade termina por ser uma análise baseada na teoria da diversidade da comunicação e da cultura. Um estudo sobre a mudança social na cultura e um estudo sobre a viabilidade da mudança social na negociação da diversidade somente fazem sentido na condição de compreensão da mudança em si mesma como uma questão da cultura, como um esforço da cultura, pois a cultura está nos níveis de formação de mudança, assim como a mudança é o nível de formação da cultura. Então, o que supomos ser a cultura? Essa questão está sob consideração assim como está o interesse na mudança do ponto de vista. Onde não há tanto interesse, nada mudará. A vontade de mudança sempre está de prontidão para a interrupção autorreflexiva (inteligência) das rotinas.

Então, esta é a tarefa deste artigo: concentrar-se em problemas culturais de diversidade e em um referencial crítico da identidade ou do etnocentrismo no âmbito de uma explicação da cultura da comunicação ou de uma explicação baseada na teoria da comunicação da cultura. Referindo-se a este conceito misturado de comunicação e cultura (BAUER, 2003), a ideia não é encontrar novas soluções para velhos problemas, mas criar problemas novos e atrativos. A solução de um problema dessa dimensão, como o que coloca a cultura da diversidade, não é resolver todos os problemas, mas trazer à tona os problemas que devem ser organizados e encarados pela sociedade civilizada, democraticamente, a fim de gerenciar a comunicação transcultural com as minorias, de forma que:

- $\quad$ essas minorias se percebam como um corpus social integrado e totalmente aceito na sociedade em que elas vivem.

- a sociedade tome consciência do potencial cultural e social das minorias.

- ambas as partes reconheçam que uma sem a outra nunca completará o conceito de identidade cultural de amálgama social que elas querem representar.

Isso significa que a análise teórica da cultura da diversidade, ao se relacionar com os contextos da mídia cultural e da prática comunicacional (cultura da mídia), deveria oferecer uma nova perspectiva de problematização para milhares de exortações dos direitos humanos, para milhares de alertas sobre os princípios de democracia ou para milhares de reivindicações de liberdade de comunicação e de mídia ou, ainda, para as frequentes invocações da razão. É importante estar analiticamente atento para as seguintes experiências:

- qualquer mudança cultural, política ou estrutural gera problemas com o conceito de identidade de qualquer sociedade multiminoritária - pelo menos 
na medida em que as mudanças provocam crises e cada crise demanda mudança (diversidade como uma crise produtiva da sociedade);

- $\quad$ qualquer cultura (da diversidade) não tem apenas uma noção ideal de si mesma, mas também uma face real - pelo menos na medida em que (seguindo o conceito dos Estudos Culturais) a cultura seja compreendida como valores de uso cotidiano (BAUER, 2002), e o estilo de vida, como condições - e não como uma cerimônia de celebração da hipóstase (BROMLEY; GÖTTLICH; WINTER, 1999);

- um ponto de vista pragmático e racional sobre os problemas levanta soluções viáveis que tornam realidade um senso pragmático de viver numa cultura comum.

Nesse sentido, a maneira de olhar para as coisas decide como o sujeito de reflexão olha. Então, ele não cria apenas uma epistemologia, mas também um senso ético para romper rotinas e refletir sobre a diversidade social como um problema da cultura da diversidade, que, enfim, aparece como uma questão teórica:

- Como seria uma cultura que dá espaço para a diversidade? Ou, ainda, como dissemos anteriormente (cultura como o outro lado da comunicação): o que é a racionalidade comunicativa da cultura? É a diversidade? Ou apenas variedade? É unidade? É universalidade?

- E, por outro lado: o que é a racionalidade cultural da comunicação? É a diversidade? É a homogeneidade? É a universalidade?

\section{A racionalidade da cultura: diversidade em comunicação}

A origem não é o único ponto de referência para uma definição de cultura (e, aqui, temos uma teoria da cultura aberta, que precisa romper com a rotina cotidiana do uso da categoria), mas devem ser também considerados, como pontos de referência, as ideias e noções nunca realizadas, os horizontes e lugares de movimento, as opções de ser diferente e de futuro. Assim, a cultura se realiza por meio da criação de sentido e significado, especialmente em tempos de crises ou de desafios (perspectiva criativa). Traçar os conceitos de identidade de enquadramentos culturais do passado orienta a atenção para as categorias de raça, etnia, religião, linguagem e territórios comuns. Traçar conceitos de identidade de enquadramentos culturais desenvolvidos na relação com os desafios presentes ou com as crises (aspecto futuro) orienta a atenção para os potenciais espaços de movimento: discursos, linguagem criativa e performances não habituais.

Contudo, a competência cultural (que inclui habilidade, prontidão, autoridade e responsabilidade [BAUER, 2002] de qualquer amálgama social) apoia-se sobre:

- Fontes de informação históricas desenvolvidas por programas de assimilação e acomodação das condições ambientais de vida, que podem desenhar modelos de conhecimento e modelos de realidade (SCHMIDT, 2003, p. 34) e de equidade. 
- Recursos de desenvolvimento criativo e programas comprovados de apropriação de significado, de realidades e de condições ambientais de vida. Assim, a maneira (sociocultural) de apropriação da realidade é a comunicação (DE CERTEAU, 1988).

Do mesmo modo, a comunicação e a interação mantêm um enquadramento de referências (e mais: de ordem) da realidade (partilhando significados) por uma performance de mudança, pelo caráter e pela mídia (discurso) (FOUCAULT, 1988). A cultura (prática social significativa) mantém um enquadramento de referências que negocia a identidade coletiva pela permanente experimentação dos seus potenciais de desenvolvimento, mudança e variedade. Assim, o desenvolvimento, a mudança e a variedade podem ser tomados como as características intrínsecas da unidade e da universalidade cultural, que se expressa e que é mediada, simbolicamente, na diversidade. A diversidade é uma questão da mídia (performance) por meio da qual a cultura expressa a competência intrínseca da variedade e da pluralidade.

No contexto da reflexão sobre a racionalidade da cultura, que está baseada em mediações diversas de comunicação, parece que os conceitos de multiculturalidade, interculturalidade ou transculturalidade (HEPP; LÖFFELHOLZ, 2002) foram apenas substituídos teoricamente pelo conceito de diversidade. Por quê? Porque relativa à conexão, a diversidade aparece como uma estrutura de fundo de uma comunicação inter, multi, ou transcultural. E mais: a cultura é um conceito de unificação, uma construção de unidade, que somente faz sentido se assumida na diferença (DELEUZE, 1992).

Assim, podemos dizer que a racionalidade da cultura mantém o desenvolvimento por meio das mudanças, num equilíbrio ecológico específico de apropriação entre assimilação e acomodação. De acordo com o conceito de Jean Piaget (1972), a inteligência (social) é um equilíbrio cognitivo entre assimilações. Não é só falar sobre a cultura como um ambiente de prática social da diversidade, mas nos perguntarmos se ela deve ser como nós pensamos que é.

\section{A racionalidade na comunicação: diversidade na cultura}

A comunicação é uma questão de complexidade cultural. Há muitas possibilidades e oportunidades de dar um sentido ao processo de troca de informação de todos os lados da parceria, dos produtores, dos mediadores e dos consumidores. Não há uma lex naturalis e não há protocolos metafísicos que ditem como a comunicação tem que ser feita, nem como ela deve parecer. Não há regulação física. Tudo o que nós sabemos e pensamos sobre a comunicação (o que fazer, como fazer e por que fazer assim ou de outra forma) é resultado da compreensão do outro. É conhecimento cultural e cálculo cultural. Assim, a racionalidade da (na) comunicação é a ideia de que esta cultura de (na) comunicação está presente na noção coletiva do uso aceitável do sentido. A racionalidade da comunicação é o programa intrínseco de ações comunicativas que mantêm e criam cultura, assim como 
a racionalidade da cultura está na manutenção de estruturas de comunicação. Isso cria um sentido analítico para distinguir entre os diferentes níveis de racionalidade de comunicação:

- Racionalidade ética: ética é um acordo de orientação socialmente estruturado, pelo qual damos sentido moral e valor para nossas atividades comunicativas. Esta é uma dimensão de competência na qual se decide a quais valores daremos prioridade e em quais situações: egocêntrico ou orientado ao outro, ou orientado aos valores subjetivos.

- Racionalidade estética: a comunicação precisa de signos, e signos estruturam sentidos. Esta é uma dimensão da competência comunicativa na qual se decide pelo signo "certo" e por sinais. Essa pode ser, de alguma forma, uma decisão ecológica para equilibrar as possibilidades e os limites dos usos dos signos comunicativos com foco na sustentabilidade.

- Racionalidade pragmática: a habilidade de decidir pelas ações comunicativas que seguem uma lógica de sucesso em situações especiais.

Em outras palavras: há razões suficientes para desenvolver (pessoal e publicamente) a comunicação pela experiência (experimentando) comunicativa, porque não há outras limitações para o ato em comunicação, apenas limitações culturais.

A cultura e um programa de uso e de reconhecimento de valores de atos de desempenhos sociais são, ambos, um indicador, mas, também, um quadro de controle de referenciais para a comunicação. Prejudicar os valores da comunicação (desenvolvimento cultural) é prejudicar valores de arranjos culturais pelos quais eles são incluídos (integração) ou excluídos (segregação) da comunidade. Compreender a cultura dessa forma implica que, se a cultura for a racionalidade da comunicação, a comunicação não seja apenas recurso de modelos de afirmação de conhecimento e realidade (desenvolvidos a partir de programas culturais), mas também recurso de criação e construção de horizontes culturais, de novos quadros de sentido e significado - pelo menos, e especialmente, quando sociedades/comunidades são desafiadas pelas crises. É a comunicação que decide entre similaridade/equidade e variedade. Não há outro pano de fundo unificador. Então, a inovação (resolução de problemas) e a racionalidade intrínseca são uma questão de comunicação. Esse é o foco de competência para desenvolver uma nova forma, performance, de orientação cultural - de fato - na diversidade.

\section{Comunicação: oportunidade e desafio da diferença}

A comunicação não é apenas uma estratégia social de redução da complexidade (LUHMANN, 1974, p. 292). A complexidade da vida não é algo que existe fora da comunicação. Ela não é uma característica das coisas ou dos eventos. Ela é uma característica do processamento das coisas; um caráter na doação de significados para 
as coisas e os eventos; uma característica da construção de realidade e sentido; um efeito da comunicação. Mas, por outro lado, a comunicação não é uma realidade (relevante); não é uma realidade mais fácil ou mais complexa que outra. Assim, a comunicação é o (único) recurso da criação de complexidade, porque misturamos, descrevemos nossa experiência, nossa posição de experiência com a percepção do que experimentamos. Criamos realidade pela percepção em referência aos conceitos que já aprendemos a usar, para que eles permaneçam na mente como um recurso (reserva) de redução de complexidade de percepção. Obviamente, nós temos a inclinação de acomodar novas cenas das experiências pela nossa capacidade de exercitá-las ou de suportá-las. Essa inclinação tem uma correspondência lógica, que é: a unificação da verdade. Teorizamos a realidade do significado como a representação da verdade, assim como pensamos que o sujeito de percepção existe como o vemos, indo para além e para fora de qualquer percepção. As coisas são como nós olhamos para elas. Nas histórias e discursos (SCHMIDT, 2003), nós permanecemos naqueles modelos de realidade, nós os usamos na reconstrução da realidade, especialmente no novo e nas conexões não habituais e, por eles, temos certeza (justificativa) de que as coisas não são nem podem ser de maneira diferente de como nós as vemos. Nesse sentido, para compreendemos um ao outro, só precisamos de uma maneira de trocar (realizar) experiências, a que chegaremos (pela negociação) ao concordarmos (consenso) e vermos a mesma coisa da mesma maneira. Então, nós achamos que encontraremos o sujeito como ele é se eliminarmos a visão errada. E chegamos a uma unidade de entendimento na qual afirmamos que há somente uma maneira de compreender a realidade. Ir para além disso é uma questão de privilégio, de sabedoria, de conhecimento ou de educação.

Exatamente essa visão construtiva de realização dá a opção de pensar que a capacidade de comunicação não serve apenas para reduzir a complexidade de unidades de ordem, mas também para fazer diferença. Se não há outro protocolo da realidade além da observação, então o ponto de observação decide sobre a realidade. O sujeito da descrição coincide com a descrição do sujeito (MITTERER 2000). Realizar essa construção faz sentido para aumentar o poder da diferenciação e distinção como uma maneira conscientemente criativa na teoria e prática da comunicação. O método mais racional é configurá-la numa ruptura. Há dois modelos de ruptura:

- A ruptura metodológica: descreve uma sociedade que está numa ruptura metodológica. Isso não é nada mais que um jeito de compreender o cálculo de uma descrição e descrever o cálculo. Ao descrever a observação calculadora de uma sociedade, esta se torna uma performance descritiva. Talvez isso seja (já) uma forma de esclarecimento e explicação, e talvez isso já ajude em ganhos de perspectivas.

- A ruptura inteligente: descreve uma sociedade em relação a um ponto de referência crítico. Éum pouco mais queapenas uma descrição. Elaéuma descrição da descrição, 
a observação da observação da sociedade. A ruptura inteligente coloca a observação de um sujeito dentro do sujeito da observação. Isso exige uma decisão de perspectiva, que só é possível depois de um processo de distinção entre diversas opções, a fim de ser capaz de distinguir, entre essas opções, os seus critérios de distinção. Assim, a escolha dos requisitos permite uma escolha de configurações, porque os requisitos dão orientação ao desempenho do significado e do sentido por meio das configurações. Então, as configurações podem ser usadas como requisitos de (próximas) configurações (SCHMIDT, 2003, p. 27). A melhor maneira de esclarecer criativamente é a ruptura inteligente. Ela é, de certa forma, uma intervenção no aprendizado (auto-reflexivo) e dá a chance para mudar o ponto de vista.

Nesse contexto, novamente, faz-se necessário levantar a questão das competências. A habilidade, a prontidão, a autoridade e a responsabilidade de decidir pelos princípios do diálogo são uma competência de racionalidade cultural, que diz: se há algum desejo da comunicação sustentável, e se a própria posição é clara e estável, por que evitar se envolver com um outro ponto de vista? Isso faz mais sentido pelo interesse na diferença do que na afirmação das próprias posições. É uma espécie de racionalidade ética que desloca a atenção para o interesse dos outros, se você quer que outros se envolvam com os seus interesses. A racionalidade ética é a escolha de uma observação crítica da observação, é a regra da regra. Mas a ética precisa de discurso público, que seja um programa culturalmente negociado de esclarecimento, para sair da crise e em referência às crises.

\section{Diversidade: mudança e desafio da identidade}

O grande desafio social, atualmente, está em viver em mundos diferentes e sincronizar as situações a uma unidade da própria vida. As ciências sociais tentam criar conceitos, a fim de oferecer códigos de explicação e classificação, mas também a fim de oferecer modelos de novos contornos de união social. A cultura desde sempre joga com uma grande regra de reunião de indivíduos ou grupos. A diversidade é um desses conceitos que indicam novas condições de autocompreensão societal. Existem duas linhas opostas de pensamento sobre a discussão da identidade na tradição da teoria dos Estudos Culturais (LIENHART, 2002):

- O conceito de essencialismo: o essencialismo parece estar profundamente enraizado nas sociedades ocidentais. Acredita que todo ser humano tem uma "essência" do eu, chamada de identidade. Seguindo essa crença, todo indivíduo nasceria com uma essência fixa de identidade (qualidades físicas e psicológicas), realizadas pelo sexo, pela raça e pela etnia. Com base nesse conceito estratégico, o essencialismo foi, muitas vezes, usado para pressupor a identidade humana como uma entidade estável com uma finalidade prática ou política específica. 
Depois de revelar que o conhecimento sobre a cultura era uma construção, ficou claro que a formação da raça e a formação sexual só tinham significado no contexto da criação de uma identidade cultural, não eram construídas por elas mesmas, mas como códigos da cosmologia social. A etnia é uma categoria especial. Por um lado, ela é uma categoria anti-essencialista, e por outro na prática política -, ela é estrategicamente usada como uma categoria essencialista. A etnia é também um conceito cultural centrado no partilhamento de normas, valores, crenças, símbolos culturais e práticas. A formação de grupos étnicos apóia-se no partilhamento de significantes culturais, que ganham significado pela particularidade de contextos históricos, sociais e políticos, e que incentivam um sentimento de pertença baseado na ancestralidade mitológica comum (BARKER, 2000, 195).

- O conceito de relativismo: esta teorização de identidade torna-se uma das questões dominantes na tradição dos Estudos Culturais e, também, na filosofia pós-moderna (KEUPP, 1999): a identidade é assumida como resultado de um patchwork da observação da observação, uma avaliação do interesse de autonomia, soberania e autoconfiança. Ela é, então, construída culturalmente, uma questão de relações de pensamento, de diferenciação da observação e da avaliação. O conceito de relativismo não insinua identidade como uma característica naturalmente dada (ontológica), mas sim como uma subjetividade construída culturalmente, nas relações sociais. Por uma questão de observação (autocontrole), a identidade é um fenômeno paralelo, é formada pelas observações experimentadas por experiências paralelas e pela consciência. Os processos conscientes e inconscientes estão em execução ao mesmo tempo, um cruzando o outro.

\section{Crises de identidade: uma questão de relações difusas}

A construção da identidade é mantida culturalmente por símbolos. Não há identidade "verdadeira" fora da interação simbólica. O risco da identidade integradora vem da difusão de (difusão nas) relações sociais. Na medida em que a diversidade dos símbolos da cultura (linguagem, mídia, temas, rituais culturais das minorias) parece ser um problema político ou de identidade nacional e cria um novo tipo de "civilização cultural" (KLAUS, 2004), ela é relevante para pôr em perspectiva o problema, assim como para considerar a perspectiva da solução para entender quais são os conceitos de identidade que o discurso público, na política e na mídia, está mantendo. Isso é assumir que eles pensam nas categorias do essencialismo, que afirmam a ideia de que a declaração de identidade é apenas uma questão de espelhamento ou de dar aos outros a mesma visão. Se você olha para dentro do espelho (imagens de ou tratamento por outros), você pensa ver você mesmo ou o que 
você pensa ter sido tempos atrás. Identidade é história e futuro. É história, no sentido em que a história é a construção de narrativa de identidade e de como ela se tornou o que é. E é futuro, no sentido em que é a continuação sustentável de desenvolver o que ela foi antes e o que ela será. Como história, vemos nossa identidade como num espelho, nossa face como um mapa traçando os caminhos de tudo o que se passou antes.

Olhar dentro do espelho não é reproduzir você mesmo, é apenas mostrar a maneira como você vê a si mesmo e como deseja ser visto pelos outros. Mas você não vê a si mesmo como os outros o veem. Nesse sentido, a contribuição de outra mente, um observador de fora, fica faltando. É apenas você. Você está considerando você mesmo na consideração sobre si. Há um ponto cego, que é a sua própria posição de consideração diante de si mesmo. Para que se possa compensar essa falta e ter uma imagem integral de si mesmo, faz-se necessária outra perspectiva, o ponto de vista dos outros, principalmente, quando o ponto de vista é contraditório.

Roteiros culturais, gerados por programas culturais, não são, individualmente, destinos. Eles são um acordo entre coletivos e indivíduos, ambos desenhados a partir desse acordo. A Teoria Cultural (DOUGLAS, 1996) tem desenvolvido um modelo de rede, pelo qual podemos analisar esses roteiros de acordo com suas principais orientações:

Culturas hierárquicas: baseiam-se no princípio de uma estrutura da ordem social orientada sobre as regras de distribuição de poder. Este tipo de cultura começa a partir do momento em que as diferenças e variedades sociais ou de membros de sociedades não podem ser alteradas. Elas são um dado da existência. Os recursos de identidade são a lei e a ordem.

- Culturas individualistas: mobilidade e variabilidade das posições parecem ser típicas deste tipo de performance cultural. Tudo parece ser possível, se houver um esforço correspondente. O equilíbrio das ofertas e demandas é uma característica dominante, que gera a sensação de sucesso ou fracasso que se torna, de certa forma, um cálculo da competição. A cultura, nesse sentido, é uma luta por vantagens e prioridades. Em culturas individualistas, os membros lutam contra a coletividade. O recurso de identidade é o sucesso individual.

- Culturas igualitárias: este tipo de cultura é caracterizado por uma forte igualdade entre os membros do grupo. Não há competição, todos podem obter qualquer posição ou assumir qualquer papel. As regras não resultam da luta ou da competição, mas das relações entre seus membros. Elas são os resultados finais de relações mútuas do coletivo. Em culturas baseadas na igualdade dos membros, a coletividade é altamente idealizada. A verdade é a do coletivo. Seitas correspondem fortemente a este tipo de cultura. O recurso de identidade é a crença na unidade.

- Culturas fatalistas: grupos entendidos como uma coletividade, frequentemente de mesmo destino ou de destino similar, que seguem a tendência de resistir 
ao mainstream. Por ações como essas, eles acalmam uns aos outros com uma forma de lealdade mútua. A fonte da identidade está em algum lugar além da vida real e, em última instância, é venerada como algo sagrado. Essa instância é o recurso de formação, de recompensa e de punição.

Não há dúvida de que, em nenhuma dessas formas de pensamento, encontra-se uma aparência pura. A verdadeira cultura sempre evolui sob condição da mistura de fontes. Ela é mencionada, neste artigo, a fim de sugerir novas pesquisas. Aplicando este modelo de rede para a situação dos países do Sudeste Europeu (cf. ERDELT; VIETH, 1993) ou para países envolvidos em discussões entre o Islam e o Ocidente, encontraremos múltiplas e misturadas dimensões deste modelo de rede, o que poderia ajudar a focar no problema de perspectiva sobre os roteiros culturais e explicar por que isso é mais difícil para uma cultura (por exemplo, culturas centradas em religiões) do que para outras.

\section{Interdependência: uma categoria futura}

A cultura da diversidade, na prática, é um conceito político de interdependência na organização política, econômica e social da vida pública. Há um ciclo psicológico dado e tomado que, individualmente, mas também coletivamente, representa a sabedoria da vida: autorrespeito é a base mais saudável de respeito pelos outros. Desrespeito pelos outros sempre tem sido uma atitude agressiva. A agressão é uma falta de aceitação um mecanismo que sempre começa com uma atitude para consigo mesmo (cf. GALTUNG, 1982). Essa foi uma das mais importantes visões da "logoterapia" do psicólogo Viktor Frankl (2002), e também uma das mais simples, que a autoaceitação é o primeiro passo em direção a uma vida significativa. Mas, claro, este é um longo caminho de negação e de defesa à aceitação, adaptação e - finalmente - à integração (BENETT, 1998). A autoaceitação começa com a decisão de aceitar os outros. Respeitando-se os outros traz respeito de volta - e este é o efeito mais importante - dá-se espaço de manobra para chegar ainda mais perto de si, criando e exercitando os potenciais não desenvolvidos. Assim, a autenticidade permite moldar a identidade por meio de mudanças de acordo com as suas condições de vida.

Um conceito saudável de identidade opera abertamente e ofensivamente: experimentando com os outros, você experimenta a si mesmo e aprende a expressar a identidade de novas maneiras. Negociar a identidade no contexto das instituições nacionais e internacionais (relações públicas), bem como no contexto do discurso nacional e internacional (a mídia), trata-se de uma questão de desempenho e de competências comunicativas, de consciência, de habilidade criativa, de prontidão e de responsabilidade para atrair outra atenção para o próprio interesse, desenvolvendo a mente aberta para os interesses dos outros. Essa habilidade é um esforço ético (um esforço de ir criando consciência e de reflexão crítica), que precisa de autoexpressão proativa e de comunicação aberta sobre fundamentos culturais dentro das várias nações ou dos grupos étnicos 
(BAUER, 2002). A ausência de comunicação interna (que significa descobrir e aceitar a diversidade ou a variedade interna) indica uma falta de autoconhecimento e autoconfiança - que só pode ser curada por meio da atenção e aceitação dos olhares dos outros. A fim de manter a identidade no âmbito da ordem simbólica da sociedade, precisamos da afirmação contínua da identidade, construindo signos e termos. Obviamente, há uma necessidade de apoio contínuo dos três registros (realidade, imaginação e conceito simbólico) (LACAN apud BRACHER, 1993), que é satisfeita pela contínua reprodução da teorização sobre o mundo e sobre o conhecimento de si mesmo.

Por mais de dois séculos, o paradigma da identidade nacional era a independência. Em um mundo multidimensional e conectado, no entanto, a identidade se tornou um produto construtivo da comunicação e da cooperação, e a independência torna-se uma função da relação de parceria. Como resultado, o novo paradigma da identidade em um mundo multifacetado é a interdependência. Identidade e identificação são resultados do diálogo e da autorrealização das nações. As minorias e as comunidades se tornam reais através de uma abertura, de um interesse subterrâneo de compreensão do outro. Nada oferece maior oportunidade - e também maior desafio - de conhecer e aceitar a si mesmo do que o engajamento com os outros e a compreensão dos outros.

Nesse contexto, o papel das mídias tem sido repensado. Tornou-se um aspecto notável das pesquisas em comunicação que os antigos pontos de referência na formação de identidade - fronteiras da religião, cultura, etnia, nacionalidade, raça, etc. - tenham sido substituídos por aspectos muito mais móveis, híbridos e virtuais nos modelos de discurso da comunicação midiática. A mídia, como agências de discurso público, tem que assumir a tarefa da reflexão crítica sobre o funcionamento da sociedade. Ela é o instrumento de uma catarse cultural, quando e onde a sociedade tem necessidade de restaurar-se ou reinventar-se.

A mídia tem a capacidade conectiva para observar a conversação pública (metacomunicação); para aumentá-la onde a informação é muito limitada e enriquecê-la onde o conteúdo discursivo é muito estreito ou muito raso; para intervir a partir do exterior quando a conversação é muito introvertida; para orientar a partir de dentro, quando o discurso se perde na tradução. Ao mesmo tempo em que a complexidade dos programas é reduzida por razões financeiras, essa redução passa a ser também sua responsabilidade na devolução de uma complexidade razoável para permanência da vida social e política.

Mobilizar essa autoconsciência crítica é uma questão de competência no viver e sobreviver sob condições de um ambiente em constante mudança; esta é uma visão pragmática da ética e um uso ético na prática. Esse horizonte pragmático e ético de autorrealização tem de ser trazido para o discurso público; esta é uma espécie de violação de regra inteligente e terapêutica - no contexto social - que só pode ser feita pelo tipo de poder coletivo representado pela mídia. Como a mídia são as agências tópicas de interação social, ela representa a competência social de uma sociedade, para a qual a auto-observação crítica é uma das competências-chave. 
Isso, obviamente, exige uma cultura midiática que se preocupe com as apostas de todos os indivíduos participantes, dos povos e das instituições, em que os proprietários, editores, jornalistas e o público - todos por suas próprias capacidades - partilhem a responsabilidade da consciência pública.

Tradução de Ana Cecília Aragão Gomes

Thomas Bauer é professor emérito da Universidade de Viena. Foi diretor da Faculdade de Ciências da Comunicação e professor convidado de numerosas universidades estrangeiras na Ásia, na América e na Europa. É autor, entre outros livros, de Kommunikation wissenschaftlich denken. Perspektiven einer kontextuellen Theorie gesellschaftlicher Verständigung (2014) (Pensar a comunicação como ciência. Perspectivas de uma teoria contextual do entendimento social).

thomas.bauer@univie.ac.at | www.thomasbauer.at

\section{Referências}

BARKER, C. Cultural Studies: Theory and Practice. London: Sage, 2000.

BAUER, T. A. Die Kompetenz ethischen und ästhetischen Handelns: Medienethik aus medienpädagogischer Perspektive. In: KARMASIN, M. (Hrsg.). Medien und Ethik. Stuttgart: Reclam, 2002. p. 194-219.

. Medienpädagogik als Mediationsagentur zwischen Medienökonomie und Medienkultur. In: ALTMEPPEN, K.; KARMASIN, M. (Hrsg.). Medien und Ökonomie. Bd. 1/1: Grundlagen der Medienökonomie: Kommunikations- und Medienwissenschaft, Medienwirtschaft. Wiesbaden: Westdeutscher Verlag, 2003. p. 115-138.

.Vom Strukturblick zum Kulturblick. Entwürfe zu einem Blended Theory-Modell. In: KARMASIN, M.; WINTER, C. (Hrsg.). Kulturwissenschaft als Kommunikationswissenschaft. Projekte, Probleme und Perspektiven. Wiesbaden: Westdeutscher Verlag, 2003a. p. 127-167.

BENNETT, M. Basic Concepts of Intercultural Communication. Selected readings. London: Intercultural Press, 1998.

BLUMER, H. A. Symbolic Interactionism. Englewood Cliffs: Prentice-Hall, 1969.

BRACHER, M. Lacan, Discourse, and Social Change. A Psychoanalytic Cultural Criticism. Ithaka/ London: Cornell University Press, 1993.

BRAH, A. Cartographies of Diaspora. Contesting Identities. London: Routledge, 1996.

BRAIDOTTO, R. Nomadic Subjects. New York: Columbia University Press, 1994.

BROMLEY, R.; GÖTTLICH, U.; WINTER, C. (eds.) Cultural Studies. Grundlagentexte zur Einführung. Lüneburg: zu Klampen, 1999. 
CLIFFORD, J. Travelling Cultures. In: GROSSBERG, L.; NELSON, C. TREICHLER, P. (eds): Cultural Studies. London \& New York: Routledge, 1992.

DE CERTEAU, M. Kunst des Handelns. Berlin: Merve, 1988.

DELEUZE, G. Differenz und Wiederholung. München: Fink Verlag, 1992.

DOUGLAS, M. Thought Styles. London: Routledge, 1996.

ERDELT-VIETH, A. (ed.). Sprache, Kultur, Identität. Selbst- und Fremdwahrnehmungen in Ost- und Westeuropa. Frankfurt: Peter lang. Europäische Hochschulstudien, 1993.

FABLER, M. Was ist Kommunikation? München: Fink Verlag, 1997.

FLUSSER, V. Kommunikologie. Hsg. Von Stefan Bollmann und Edith Flusser. Frankfurt: Fischer, 1998.

FOERSTER, H. Sicht und Einsicht. Reihe Wissenschaftstheorie, Wissenschaft und Philosophie, Bd. 21. Braunschweig: Vieweg, 1985.

Wissen und Gewissen. Versuch einer Brücke. Herausgegeben von Siegfried J. Schmidt. Frankfurt: Suhrkamp, 1993.

FOUCAULT, M. Der Tod des Menschen im Denken des Lebens, hg. Von Marcelo Marques. Tübingen, 1988.

FRANK, E. V. Logotherapie und Existenzanalyse. Texte aus sechs Jahrzehnten. Weinheim und Basel: Beltz, 2002.

GALTUNG, J. Beiträge zur Friedens- und Konfliktforschung. Reinbeck bei Hamburg: Rowohlt, 1982.

GEBAUER, G.; WULF, C. Spiel, Ritual, Geste. Mimetisches Handeln in der sozialen Welt. Reinbeck bei Hamburg: Rowohlt, 1998.

GIDDENS, A. The consequence of modernity. Stanford: Stanford University Press, 1990.

HALL, S. Ausgewählte Schriften. Hamburg: Argument, 1998.

HEPP, A.; WINTER, R. Kultur - Medien - Macht. Cultural Studies und Medienanalyse. Opladen: Westdeutscher Verlag, 1997.

HEPP, A. Fernsehaneignung und Alltagsgespräche. Fernsehnutzung aus der Perspektive der Cultural Studies. Opladen/Wiesbaden: Westdeutscher Verlag, 1998.

.Translokale Medienkulturen. In: HEPP, A.; LÖFFELHOLZ, M. (eds.) (Hrsg.). Grundlagentexte zur transkulturellen Kommunikation. Konstanz: UVK, 2002. p. 861-885.

HIPFL, B. Medien-Identitäten: Identifikationen, Imaginationen, Phantasien. In: BUSCH, B.; HIPFL, B.; ROBINS, K. (eds.). Klagenfurt, 2001. p. 47-70.

KEUPP, T. et al (eds.) Identitätskonstruktionen. Das Patchwork der Identitäten in der Spätmoderne. Reinbeck bei Hamburg: Rowohlt, 1999.

KLAUS, E. Cultural Citizenship. Ein kommunikationswissenschaftliches Konzept zur Bestimmung kultureller Teilhabe in der Mediengesellschaft. In: Medien- und Kommunikationswissenschaft, 2004. 2/04: 193-213.

MDI. Media Diversity Institute, Snjezana Milivojevic. Mirroring Images: Ethnic Minorities in the South East European Press, 2004. Disponível em: http:/www..media-diversity.org. Acesso em 10 Ago. 2004.

MARTIN-BARBERO, J. Communication, Culture and Hegemony. London: Newbury Park: SAGE,1993

MITTERER, J. Die Flucht aus der Beliebigkeit. Frankfurt: Fischer, 2001. 
MÜNCH, R. Dialektik der Kommunikationsgesellschaft. Frankfurt/Main: Suhrkamp, 1995.

LIENHART, A. Urban Communication. Identification and Integration through Communication in Modern/Post-modern Cities (Thesis at Vienna University), 2002.

LUHMANN, N. Systemtheoretische Argumentation. Zur Entgegnung auf Jürgen Habermas. In: HABERMAS, J.; LUHMANN, N. Theorie der Gesellschaft oder Sozialtechnologie - Was leistet die Systemforschung? Frankfurt: Suhrkamp, 1974.

PIAGET, J. Psychologie der Intelligenz. Olten: Waalter Verlag, 1972.

RABINOV, P. Anthropologie der Vernunft. Studien zu Wissenschaft und Lebensführung. Frankfurt/ Main: Suhrkamp, 2004.

SCHMIDT, S. J. Geschichten \& Diskurse. Abschied vom Konstruktivismus. Reinbeck bei Hamburg: Rowohlt, 2003.

Unternehmenskultur. Die Grundlage für den wirtschaftlichen Erfolg von Unternehmen. Weilerswist: Velbrück Wissenschaft, 2004.

TAYLOR, C. Quellen des Selbst. Die Entstehung der neuzeitlichen Identität. Frankfurt/M: Suhrkamp, 1994.

Die Formen des Religiösen in der Gegenwart. Frankfurt: Suhrkamp, 2002.

TOMLINSON, J. Internationalismus, Globalisierung und kultureller Imperialismus. In: HEPP, A.; LÖFFELHOLZ, M. (eds.). Grundlagentexte zur transkulturellen Kommunikation. Konstanz: uvk, 2002.

UDOVICIC, R. Television and multi-culture. In: MDI. Disponível em www. media.diversity.org. Acesso em Ago. 2004.

Artigo recebido em abril e aprovado em junho de 2016. 